\title{
Tests for detecting and monitoring the acute phase response
}

Children with inflammation due to infection or other tissue damage develop a systemic response which includes fever, a neutrophil leucocytosis, and an increase in concentration of several plasma proteins of hepatic origin. These changes are collectively known as the acute phase response and are mediated by cytokines, such as interleukin-1 and tumour necrosis factor, which are synthesised by macrophages that accumulate at the site of tissue damage. ${ }^{1}$ The term acute phase is ill defined but refers to the intensity rather than the duration of the inflammatory response so that a child with chronic disease may also show an increase in acute phase reactants, either intermittently or persistently.

The specificity of the acute phase response means that measurement of an increase in plasma concentration of acute phase proteins provides unequivocal evidence of inflammation and, because of the ubiquitous nature of inflammation, may therefore be used to detect a wide range of organic diseases. While bacterial infection is one of the most potent stimuli of the acute phase response, immunological, traumatic, ischaemic, or malignant damage to tissues usually evokes inflammation and thus a response. The magnitude of that response provides a guide to the intensity of inflammation or the extent of tissue involvement. ${ }^{2}$ Measurement of acute phase proteins may thus be used for either detecting organic disease, assessing the extent or activity of that disease, monitoring treatment, predicting outcome, or detecting intercurrent infection.

\section{Laboratory tests}

In paediatrics the main value of tests for detecting and monitoring the acute phase response is as an early indicator of bacterial infection in circumstances where a microbiological diagnosis is impossible or delayed. Other applications for such tests are similar to those in adults and include the monitoring of chronic inflammatory disorders such as Still's disease. It is essential to appreciate that, while the acute phase protein response is highly specific for inflammation, many disease processes are accompanied by inflammation so that a rise in acute phase proteins can never be specific for a particular disease, such as infection, and must always be interpreted in the light of the clinical picture.

The variety of tests available to monitor the acute phase response has led to controversy over which tests should be used. The poor specificity of fever is well known and determination of total and differential leucocyte counts is of limited value in the diagnosis of bacterial infection in children, ${ }^{3-6}$ although the immature:total neutrophil ratio may be more useful. ${ }^{7}$ The major area of debate, however, concerns tests for detecting an increase in acute phase proteins, the leading contenders being measurement of an individual acute phase protein, such as C-reactive protein, or tests such as the erythrocyte sedimentation rate and plasma viscosity that provide an integrated measurement of the contribution of several proteins.

Individual acute phase proteins vary not only in the rate at which their blood concentration rises after the onset of inflammation, but also in half life and in rate of catabolism in different forms of inflammation. C-reactive protein, serum amyloid A protein, and alpha-1-antichymotrypsin rise within 6 to 10 hours of injury, show large incremental increases of 10 to 1000 fold over their normal values, have short half-lives, and behave consistently in different forms of inflammation. Orosomucoid, alpha-1-antitrypsin, haptoglobin, and fibrinogen rise after 24 to 48 hours, rarely increase more than two fold, have long half lives and, with the exception of orosomucoid, show variable catabolism in some diseases. Haptoglobin and alpha-1-antitrypsin have common genetic variants which result in their deficiency. C3, C4, and caeruloplasmin generally show poor and inconsistent acute phase responses.

Of the useful acute phase proteins C-reactive protein is the most easily measured, and commercial assay kits are widely available. Unfortunately, studies of its usefulness have been bedevilled by poor standardisation and the use of non-quantitative assays. Now that an international reference standard for it has been accepted by the Expert Panel on Biological Standards of the World Health Organization there should be better standardisation of the assay between laboratories and in future clinical studies. Much of the value of measuring C-reactive protein lies in serial monitoring of the onset or resolution of inflammation and this necessitates quantitative assays rather than semi-quantitative or qualitative latex agglutination tests. Techniques that give the required rapid results include laser nephelometry ( 1.5 hour assay time), rate immunonephe- 
lometry or turbidimetry $(0 \cdot 25-0.5$ hour $)$, and enzyme immunoassay $(0 \cdot 25$ hour $)$.

The erythrocyte sedimentation rate is probably still the most widely measured index of the acute phase response. The relative contribution of different plasma proteins to erythrocyte sedimentation are fibrinogen $55 \%$, alpha-2-macroglobulin $27 \%$, the immunoglobulins $11 \%$, and albumin $7 \%$. The test is also affected by red cell characteristics and, in particular, their number, with a decrease in haematocrit increasing the erythrocyte sedimentation rate. Plasma viscosity, though not yet widely used, is unaffected by red cells and, unlike the erythrocyte sedimentation rate, may be measured on stored samples. It reflects primarily the plasma concentration of fibrinogen and immunoglobulins. Both tests are thus non-specific and reflect changes in a number of proteins, of which the acute phase reactant component is predominantly fibrinogen. Thus, in parallel with changes in fibrinogen concentration, both tests respond slowly to inflammation, not showing an increase until 24 hours or more after the onset and falling slowly to normal with a half time of 96-144 hours on resolution of inflammation. They do, however, also respond to increases in immunoglobulins, immune complexes, and other proteins and thus cast a broader net for the detection of disease than does any acute phase protein alone. They have the advantage of being less affected by acute events, such as a viral infection, that cause a transient increase in sensitive acute phase proteins such as $\mathrm{C}$-reactive protein.

Tests of erythrocyte sedimentation are, however, not well suited to paediatric use owing to their requirement for a relatively large blood sample, although microsedimentation tubes that require a smaller volume of blood are available and published evaluations $^{8-10}$ have shown acceptable correlation with the selected Westergren method of the International Committee for Standardization in Haematology. ${ }^{11}$ In addition, the sensitivity of the erythrocyte sedimentation rate to haematocrit means that neonatal polycythaemia and childhood anaemia will give false low and false high values respectively. Hypofibrinogenaemia of the newborn may also cause false low results for both erythrocyte sedimentation rate and plasma viscosity. ${ }^{2}$ of the two tests plasma viscosity is more suited to paediatric practice but instrument manufacturers have been slow to develop automated viscometers for clinical use and the sedimentation rate is still widely used because it is available.

\section{Acute disease and infection}

When the clinical history is of less than 24 hours' duration, C-reactive protein is the acute phase protein of choice owing to its rapid response (6-10 hours) and large incremental increase from concentrations of less than $10 \mathrm{mg} / \mathrm{l}$ in normal serum (including that of premature infants and neonates). Typical serum concentrations would be: mild inflammation and severe viral infection, $10-40 \mathrm{mg} / \mathrm{l}$; active inflammation and bacterial infection, 40$200 \mathrm{mg} / \mathrm{l}$; and severe bacterial infection and burns, $200-400 \mathrm{mg} / \mathrm{l}$.

Measurement of C-reactive protein is of particular value in paediatric practice as an indicator of invasive bacterial infection (viral infection causing little or no increase) and the subsequent fall in serum concentration (half time of 48 hours) on resolution of the inflammatory focus is useful for monitoring the efficacy of treatment. There is no absolute serum concentration of $\mathrm{C}$-reactive protein that is diagnostic of bacterial infection, although $40 \mathrm{mg} / \mathrm{l}$ has been claimed to give higher specificity, with acceptable sensitivity, than $20 \mathrm{mg} / \mathrm{l}$. In a study of 131 children who had been febrile for more than 12 hours, a serum concentration of $40 \mathrm{mg} / \mathrm{l}$ or more on admission had a sensitivity of $79 \%$ and a specificity of $90 \%$ for the detection of bacterial infection, while an erythrocyte sedimentation rate of $30 \mathrm{~mm} /$ hour or more had a sensitivity of $91 \%$ and a specificity of $89 \% .{ }^{13}$ A similar study of infected neonates clearly showed that sensitivity varied with the level of C-reactive protein considered, the definition of infection used, and the time at which the blood was taken in the course of the disease. ${ }^{7}$ Specificity also depends on whether patients with obvious non-infective pathology are excluded from the study group, as they clearly should be,${ }^{14}$ and on whether serial measurements are made. ${ }^{15}$ In a study of children with suspected meningitis a serum concentration of $20 \mathrm{mg} / \mathrm{l}$ or more indicated a bacterial rather than viral origin. ${ }^{16}$ In immunocompromised patients with leukaemia concentrations of $30 \mathrm{mg} / 1^{17}$ and $100 \mathrm{mg}^{18-20}$ have been used to diagnose infection. In premature rupture of the membranes a C-reactive protein concentration of greater than $125 \mathrm{mg} / \mathrm{l}$ gave a positive predictive value of $96 \%$ and a negative predictive value of $89 \%$ for chorioamnionitis and, owing to the poor success rate of amniocentesis, was felt to be the more useful diagnostic test in this clinical situation. Interestingly the erythrocyte sedimentation rate showed a positive predictive value of $100 \%$ and a negative predictive value of $67 \%$ in this study. ${ }^{21}$

Measurement of $\mathrm{C}$-reactive protein is most useful in the rapid diagnosis of infection if serial quantitative measurements are made and a progressive increase can be shown in the first 48 hours. If single measurements are used their value lies in excluding 
or confirming infection 24 hours after the first clinical symptoms, at which time the erythrocyte sedimentation rate may give similar information.

\section{Chronic disease}

In the diagnosis of chronic disease there may be an intermittent or persistent increase in acute phase proteins but the nature of the hyperproteinaemia is more complex than in the first 24 hours of an illness and no single acute phase protein can be considered to be representative. Such tests as those that measure erythrocyte sedimentation rate and plasma viscosity, being sensitive to the combined effect of several acute phase proteins and immunoglobulins, should therefore be used. Although changes in response to treatment are more rapidly mirrored by $\mathrm{C}$-reactive protein, erythrocyte sedimentation rate and plasma viscosity have the advantage of being less affected by intercurrent illness such as a minor infection. A combination of $\mathrm{C}$-reactive protein and either erythrocyte sedimentation rate or plasma viscosity may therefore provide the most useful information on which to base therapeutic intervention. $^{2}$

\section{Conclusion}

No one laboratory test satisfactorily reflects all aspects of the acute phase response and the choice of test is determined by the length of clinical history and the nature of the disease process. Serial measurement of $\mathrm{C}$-reactive protein by a rapid, quantitative, and appropriately standardised assay is the test of choice for detecting and monitoring the acute phase protein response of acute inflammatory disorders such as infection in children. The assay is only worthwhile as a screening procedure for infection if the clinical context is well defined and other clinically detectable inflammatory diseases are excluded. With these provisos, a concentration of Creactive protein above $40 \mathrm{mg} / 1$ may be used to confirm infection, its diagnostic value increasing with time after the onset of symptoms to a maximum at 48 to 72 hours. In contrast, diagnosis and monitoring of chronic inflammatory disease is best undertaken by the measurement of erythrocyte sedimentation rate or plasma viscosity, although measurement of C-reactive protein may be useful in detecting an early response to treatment.

\footnotetext{
References

' Dinarello CA. Interleukin-1. Rev Infect Dis 1984;6:51-5.

2 Whicher JT, Dieppe PA. Acute phase proteins. Clin Immunol Allerg 1985;5:425-46.
}

${ }^{3}$ Moodley GP. The micro-erythrocyte sedimentation rate in black neonates and children. $S$ Afr Med $J$ 1981;60:545-7.

${ }^{4}$ Rasmussen NH, Rasmussen LN. Predictive value of white blood cell count and differential cell count to bacterial infections in children. Acta Paediatr Scand 1982;71:775-8.

${ }^{5}$ Hindocha P, Campbell CA, Gould JDM, Wojciechowski A, Wood CBS. Serial study of C-reactive protein in neonatal septicaemia. Arch Dis Child 1984;59:435-8.

${ }^{6}$ McCord FB, Jenkins JG, Lim JHK. C-reactive protein concentration as screening test for bacterial infection in febrile children. Br Med J 1985;291:1685-6.

${ }^{7}$ Mathers NJ, Pohlandt F. Diagnostic audit of C-reactive protein in neonatal infection. Eur J Pediatr 1987;146:147-51.

${ }^{8}$ Stuart J, Barrett BA, Prangnell DR. Capillary blood collection in haematology. J Clin Pathol 1974;27:869-74.

9 Barrett BA, Hill PI. A micromethod for the erythrocyte sedimentation rate suitable for use on venous or capillary blood. J Clin Pathol 1980;33:1118-20.

10 Hackett MC, Hinchliffe RF, Laycock BJ, Lilleyman JS Erythrocyte sedimentation rate: evaluation of a commercial capillary-ESR tube in a paediatric haematology laboratory. Med Lab Sci 1983;40:183-5.

11 International Committee for Standardization in Haematology. Recommendation for measurement of erythrocyte sedimentation rate of human blood. Am J Clin Pathol 1977;68:505-7.

12 Buchan PC. Evaluation and modification of whole blood filtration in the measurement of erythrocyte deformability in pregnancy and the newborn. Br J Haematol 1980;45:97-105.

13 Putto A, Ruuskanen O, Meurman O, et al. C-reactive protein in the evaluation of febrile illness. Arch Dis Child 1986;61:24-9.

14 Bennish M, Beem MO, Ormiste V. C-reactive protein and zeta sedimentation ratio as indicators of bacteremia in pediatric patients. J Pediatr 1984;104:729-32.

15 Ainbender E, Cabatu EE, Guzman DM, Sweet AY. Serum Creactive protein and problems of newborn infants. $J$ Pediatr 1982;101:438-40.

16 Peltola HO. C-reactive protein for rapid monitoring of infections of the central nervous system. Lancet 1982;i:980-3.

17 Starke ID, De Beer FC, Donnelly PJ, et al. Serum C-reactive protein levels in the management of infection in acute leukaemia. Eur J Cancer Clin Oncol 1984;20:319-25.

18 Mackie PH, Crockson RA, Stuart J. C-reactive protein for rapid diagnosis of infection in leukaemia. J Clin Pathol 1979;32: 1253-6.

19 Rose PE, Johnson SA, Meakin M, Mackie PH, Stuart J. Serial study of C-reactive protein during infection in leukaemia. J Clin Pathol 1981;34:263-6.

${ }^{20}$ Grønn M, Slørdahl SH, Skrede S, Lie SO. C-reactive protein as an indicator of infection in the immunosuppressed child. Eur $J$ Pediatr 1986;145:18-21.

${ }^{21}$ Hawrylyshyn P, Bernstein P, Milligan JE, Soldin S, Pollard A, Papsin FR. Premature rupture of membranes: The role of Creactive protein in the prediction of chorioamnionitis. $A m \mathrm{~J}$ Obstet Gynecol 1983;147:240-6.

J STUART

Department of Haematology, Medical School, University of Birmingham, Birmingham B15 2TJ

J T WHICHER Department of Chemical Pathology, Old Medical School, University of Leeds, Leeds LS2 9JT 